


\title{
Mariano Azuela y José Clemente Orozco en diálogo: apuntes sobre las ilustraciones de la primera edición en inglés de Los de abajo
}

\section{Mariano Azuela and José Clemente Orozco in dialogue: notes on the illustrations of the first English edition of Los de abajo}

\author{
Daniel Avechuco Cabrera \\ Universidad de Sonora, México
}

\begin{abstract}
Resumen: En 1929 se publicó en Estados Unidos Los de abajo, de Mariano Azuela, con ilustraciones de José Clemente Orozco. El pintor mexicano había llegado en 1927 a la Gran Manzana, desde donde le daba a conocer al público estadounidense los desastres revolucionarios a través de una colección de dibujos, grabados y acuarelas, más tarde intitulada México en Revolución. Dado que parecen derivar artísticamente de esa colección, los dibujos con que Orozco ilustra la novela de Azuela no son una mera réplica gráfica de los contenidos del texto, sino que constituyen una visión particular de la lucha armada. El presente trabajo pretende explicar cómo se relacionan las dos visiones artísticas sobre la Revolución que confluyen en la primera edición en inglés de Los de abajo.
\end{abstract}

Palabras clave: Revolución Mexicana, ilustración, novela, Los de abajo, violencia.

Abstract: In 1929 Los de abajo, by Mariano Azuela, was published in the United States, with illustrations of José Clemente Orozco. The Mexican painter had arrived in 1927 to the Big Apple, from where he made 
known to the American public the revolutionary disasters through a collection of drawings, engravings and watercolors, later entitled Mexico in Revolution. Since they seem to derive artistically from that collection, the drawings with which Orozco illustrates Azuela's novel are not a mere graphic replica of the contents of the text, but constitute a particular vision of the armed struggle. The present paper tries to explain how they relate the two artistic visions about the Revolution that converge in the first English edition of Los de abajo.

Keywords: Mexican Revolution, Illustration, Novel, Los de abajo, Violence.

Recibido: 1 marzo de 2018 Aceptado: 23 de julio de 2018

\section{Introducción}

- 1 análisis de un texto literario ilustrado nos enfrenta a una serie Cde problemas de carácter semiótico, metodológico e incluso epistemológico. De entrada, cabe considerar la imagen como paratexto, es decir, un elemento auxiliar que contribuye a la comprensión del texto (Alvarado) y a la posible expansión de su sentido (Genette, 2001: 13). Desde esta perspectiva, las ilustraciones deben tratarse como signos dependientes de y condicionados por el marco literario en que se hallan insertas. No obstante, a diferencia de otros paratextos, como las dedicatorias y los epígrafes, la imagen implica la inclusión de una visión y una sensibilidad distintas a las del autor del texto, aun cuando el ilustrador pretenda limitarse a representar gráficamente determinados pasajes de la obra. Esto, claro, torna todavía más compleja la relación letra-imagen.

En la primera edición en inglés de Los de abajo, de Mariano Azuela, publicada en 1929 en Nueva York con ilustraciones de José Clemente Orozco, el tema de la visión y sensibilidad dobles está tanto más acentuado cuanto que la del pintor es una presencia de mucho carácter, reacio, con frecuencia, a seguir las directrices de la 
palabra. Además, debe tenerse en cuenta que las dos visiones autorales que dialogan en la primera edición en inglés de Los de abajo se encuentran determinadas por coordenadas espaciotemporales distintas: Azuela escribió la novela durante la Revolución -si bien ya en su fase final-y pensando en el lector mexicano, ${ }^{1}$ mientras que las ilustraciones fueron creadas para el mercado estadounidense y cuando el Estado mexicano derivado del proceso revolucionario empezaba a colocar sus cimientos. Finalmente, no puede dejar de apuntarse que, aunque el escritor e ilustrador compartieran sensibilidad y visión y crearan a partir de condiciones espaciotemporales idénticas, los sistemas semióticos en cuestión, el icónico y el verbal, proponen necesariamente formas diferentes de representar y descodificar la realidad.

Dicho lo anterior, con este trabajo me propongo no tanto ahondar en la compleja relación entre las manifestaciones sígnicas de dos sistemas semióticos distintos que coinciden en la primera edición en inglés de Los de abajo, sino aproximarme a los modos en que los discursos icónico y verbal visualizan el rostro más caótico de la guerra; soy consciente de las limitaciones de este objetivo, pero debe entenderse como una primera aproximación al problema. Así, me interesa señalar en qué medida las ilustraciones se subordinan a las palabras y en qué medida desoyen sus directrices. Si bien centraré mis explicaciones de las divergencias en la respectiva visión social y política de Mariano Azuela y José Clemente Orozco, cuando lo estime conveniente incluiré reflexiones tanto de índole semiótica como relativas a las condiciones de producción, pues evidentemente estos factores son parte fundamental del objeto de estudio.

${ }^{1}$ Aunque la versión que tradujo Enrique Munguía es la de 1920, que posee diferencias sustanciales con respecto a la primera edición, de 1915. 


\section{Orozco lleva la Revolución a Manhattan}

En noviembre de 1927, José Clemente Orozco sale de México rumbo a Nueva York, obligado por las necesidades económicas y un clima político hostil que llegó a complicarle mucho su labor artística. Ahí se encuentra con Alma Marie Prescott Sullivan Reed, la periodista californiana mejor conocida como Alma Reed, quien había estado en México como corresponsal del New York Times y quien desde entonces fungirá de puente entre el pintor mexicano y algunos círculos intelectuales de Manhattan.

En México, Orozco había empezado a dibujar escenas de la Revolución, actividad que continuó en la Gran Manzana. ${ }^{2}$ La serie, inicialmente titulada Horrores de la Revolución, ${ }^{3}$ no tuvo la mejor

${ }^{2}$ Para ahondar en el origen de los dibujos, véase el capítulo II de Muralism Without Walls: Rivera, Orozco, and Siqueiros in the United States, de Anna Indych-López, trabajo consignado en la bibliografía.

${ }^{3}$ El título evoca, claramente, los Desastres de la guerra, la serie de grabados de Goya. A pesar de que Orozco era un admirador confeso del pintor español, siempre le incordió que lo compararan con él. Al parecer fue José Juan Tablada el primero en señalar las similitudes: "[Orozco] merece ser llamado el Goya mexicano $[\ldots]$ por su humor amargo, su vena caprichosa, y el inquietante y casi torturante aspecto del que se vale para poner de manifiesto los esenciales de la sombría humanidad que pinta" (Tablada, 1981: 33). Cardoza y Aragón pronto se sumó a la comparación: "Fue un excepcional creador de monstruos como Bosco, Brueghel el Viejo, Goya y algunos de los grandes poetas románticos" (Cardoza, 1959: 99). Alma Reed va más lejos, pues asevera que en lo concerniente a la revelación de la barbarie de la guerra, el muralista mexicano es más profundo que el artista español: "Ni siquiera Goya en sus Horrores de la guerra ha descrito el salvajismo bélico con más espantosa sinceridad. Y ninguna obra de arte ha precisado nunca con más honradez la culpabilidad de permitir que tales escenas de carnicería se repitan contantemente en la historia, como los dibujos de Orozco" (Reed, 1955: 44). A Ignacio de la Peńa, la equiparación le sirvió para fundamentar su muy discutible interpretación psicoanalista: "Orozco, como Goya, no ama a la Humanidad, sino que la desprecia. De su acervo hostil, misantrópico, amargado, brotan esas criaturas monstruosamente anties- 
de las acogidas entre los especialistas y los dueños de las galerías: los dibujos fueron tildados de heréticos e incluso hubo quien les negó el estatus de arte por considerarlas, más bien, caricaturas políticas (Indych, 2001: 160). La exhibición que más tarde organizó Alma Reed en la galería de Marie Sterner, con el nombre menos agresivo de México en revolución, obtuvo resultados similares: "Fue obvio -dice Alma Reed-, por la recepción que abrió la exhibición de Marie Sterner en la tarde del 10 de octubre, que el elegante Manhattan no tenía interés todavía en la tragedia mexicana" (Reed, 1955: 83). Ante el patente fracaso, José Clemente Orozco seleccionó algunos dibujos y los convirtió en litografías con leves pero significativos ajustes, los cuales hicieron la diferencia:

The real "horrors" -those drawings graphically depicting violence, bodily injury, and blood- were virtually repressed. In effect, what happened to the series by the shift in title, the isolation of individual drawings from the entirety of the series, and the choices made to promote certain images through lithography, is that it became another way of representing "lo mexicano". Stereotypical subject matter -peasants, maguey plants, soldaderas- were emphasized, but the horrific vicissitudes of the civil strife and the struggles of the Mexican people would be sanitized from the series in order to effect its commercial debut in the United States. Neither the public in Mexico nor the United States in the late 1920s was ready for Orozco's horrific portrayal of revolutionary violence (Indych, 2001: 164).

El éxito de las litografías constituye un testimonio indirecto pero bastante claro del poder perturbador de la serie en su versión original, que fabulaba una lucha armada desprovista de todo componente esperanzador o por lo menos paliativo: en los dibujos se

téticas, esos rostros hórridos deformados por el odio, el vicio o la bestialidad" (Peña, 1982: 415). 
observa una Revolución sucia, ruidosa y desbocada, lo cual nos recuerda que para José Clemente Orozco, según sus propias palabras, el movimiento armado había supuesto "sainete, drama y barbarie," la calle polvosa por donde desfilaron enanos, celestinas, bufones y comandantes insolentes y alcohólicos (Orozco, 2002: 33 y 44). Dada esa suciedad y ese ruido, resulta patente la mirada distante pero enternecida y sigilosamente compasiva que, de cuando en cuando, asoma por la colección. Son los dos extremos de un mismo ambiente, el de guerra, pero no el de la guerra que respeta los lindes del campo de batalla, sino de aquella que desborda todas las fronteras. Sólo es cuestión de ver el contraste entre las piezas "El ahorcado" y "En los cerros".

Solía aseverar José Clemente Orozco que los "artistas no tienen ni han tenido nunca 'convicciones políticas' de ninguna especie, y los que creen tenerlas no son artistas" (Orozco, 2002: 27). Algunos de sus comentaristas más reputados, como Octavio Paz, Luis Cardoza y Aragón y Ermilo Abreu Gómez, parecen estar de acuerdo con las palabras del pintor, pues sostienen que su obra de contenido revolucionario no está condicionada por una interpretación política de la lucha armada. Discrepo: cuesta trabajo creer que la obra del caricaturista que vapuleó a Madero desde la redacción de El Hijo del Ahuizote y que luego militó en las filas de El Machete carezca de una perspectiva política cuando aborda la Revolución. Lo que ocurre en Horrores de la Revolución-señalamiento extensivo a las ilustraciones de Los de abajo, como veremos más delantees que Orozco se "ajusta a su vislumbramiento de realidades monstruosas" (Monsiváis, 1981), cuyo estruendo disimula los elementos a partir de los cuales se podría abstraer o al menos especular una visión política clara. A diferencia de sus homólogos, especialmente de Diego Rivera, el creador de La trinchera se empeña en enturbiar su visión política sobre la lucha armada, ${ }^{4}$ y para ello explota el caos como posible representación de

${ }^{4}$ Una de las razones de la antipatía que Orozco muestra por Rivera es el mexicanismo de éste, que en tierras extranjeras fungía de parámetro para validar el arte mexicano. Así se quejaba Orozco con Jean Charlot: "Diegoff Riveritch Romanoff: Toda una amenaza para nosotros todavía [...] aquí [Nueva York] está 
vacío de discurso. Además, debe tenerse en cuenta, como apunta Anna Indych, que las piezas de los Horrores estaban destinadas a un público estadounidense, entre cuyas exigencias no se encontraba la explicitación de una postura política con respecto al movimiento armado.

Me he detenido en Horrores de la Revolución y en algunos de sus rasgos más notorios porque considero que las ilustraciones de la primera edición en inglés de Los de abajo (1915), de Mariano Azuela, son derivaciones de dicha serie, la cual a su vez retoma viejos motivos revolucionarios de la obra orozquiana previa (Indych, 2001: 155; 2009: 16). La razón es muy simple: a Orozco se le encargó las ilustraciones de la novela en 1929, es decir, no mucho después de que trabajara en los últimos retoques de la colección y de las composiciones litográficas que de ella se desprenderían. Meses antes de que se le hiciera la petición, Anita Brenner le había escrito a Mariano Azuela para sugerirle que la edición en inglés llevara ilustraciones, después de lo cual propone al autor de Prometeo para ese quehacer: "José Clemente Orozco ha hecho dibujos, 'Horrores' los llamamos, de las cosas que son exactamente el momento emocional de Los de abajo. Debería de ilustrar su obra. Son los únicos con la fuerza debida" (Apud. Azuela, 1991: 175). El escritor jalisciense acepta la propuesta, al igual que el traductor, Enrique Munguía, quien después describirá las ilustraciones como fuertes, crueles y sensuales (Apud. Azuela, 1991: 159). Cabe aclarar que si bien para finales de los años veinte Los de abajo ya gozaba del reconocimiento de la crítica, todavía se hallaba muy lejos de ser la obra cumbre de la literatura mexicana en que se habría de

bien remachada la idea de que todos somos sus discípulos. Hablar de 'indios,' 'revolución,' 'Renacimiento mexicano,' 'artes populares,' 'retablos,', etc., etc., es hablar de Rivera" (Orozco, 1993: 57). Para Carlos Monsiváis, esa animadversión por Rivera llega incluso a repercutir en la actitud de Orozco ante el mundo: "En buena medida, con tal de separarse de Rivera, Orozco denigrará sus propias convicciones, se adherirá a un nihilismo escénico, acentuará su misantropía" (Monsiváis, 1981). 
convertir décadas más tarde. Este apunte no es anecdótico, pues de algún modo explica la desgana y el pragmatismo con que el pintor recibe la encomienda, ${ }^{5}$ actitud manifiesta en una carta que le dirige a su esposa en abril de 1929: "Otro éxito: Van a editar aquí la novela mexicana 'Los de abajo' [sic], traducida al inglés. Quieren

${ }^{5}$ De hecho, ni siquiera con el paso del tiempo Orozco parece revalorar las ilustraciones para Los de abajo. Prueba de ello es que en su Autobiografía, en la cual revisa sucintamente su obra, no le destina una sola palabra al proyecto. De esta indiferencia parecen haberse contagiado los especialistas, lo cual ya lo notamos en el propio prefacio de la primera edición en inglés de la novela, donde Carleton Beals ignora el aporte de las ilustraciones, aunque su caso quizás se justifique por el hecho de que en esa época el trabajo se Orozco debió de considerarse como un mero ornamento. A quien no se puede disculpar es a Enrique Pulpo-Walker, que le dedica un artículo completo a las confluencias estéticas de Orozco y Azuela, en el que, sin embargo, no hay una sola mención de las ilustraciones. Ocurre lo mismo con Octavio Paz, cuyo sagaz y certero análisis de la propuesta pictórica de Orozco no incluye los dibujos de Los de abajo, no obstante que, en un comentario suelto, compara al pintor con el novelista (Paz, 1987: 305). Luis Cardoza y Aragón, uno de los incondicionales más célebres del pintor, les ofrenda unas pocas líneas a las ilustraciones, aunque básicamente para concluir que no son excepcionales, a diferencia del resto de sus creaciones (Cardoza, 1959: 129). Alma Reed sí se toma unos cuantos párrafos para hablar de Los de abajo, aunque su análisis no deja de consistir en apuntes sueltos, además carentes de cualquier rigor y colmados de interpretaciones trascendentalistas (Reed, 1959: 152-153) que contradicen, me parece, el espíritu práctico con que el creador de El hombre en llamas acometió el encargo.

Quien deja los apuntes más interesantes sobre la relación entre Los de abajo y las ilustraciones de Orozco es Elizabeth García Guajardo; en su tesis de maestría, titulada Mariano Azuela y José Clemente Orozco: imágenes de la Revolución, establece un vínculo muy sugerente entre la novela y la obra del pintor mexicano. Si bien su análisis tiende a convertir algunas escenas de Los de abajo en imágenes aisladas y no como parte de una trama, y si bien dicho análisis se apoya demasiado en elementos biográficos, concuerdo en varias de sus anotaciones, como lo indicaré en su momento. Además, debe tenerse en cuenta que García Guajardo no se limita a comparar a Orozco y Azuela a partir de las ilustraciones de la novela, sino que contempla casi toda la obra del pintor. Su trabajo es mucho más abarcador, con todos los riesgos que ello implica. 
que haga yo las ilustraciones. Las haré si la fatiga me lo permite, créeme que ya estoy verdaderamente rendido y con más ganas de irme a mi casa que de ocuparme de arte" (Orozco, 1987: 153). Al final la fatiga sí le permitió a Orozco hacer las ilustraciones, y la primera edición en inglés de Los de abajo fue publicada unos meses más tarde con el título The Under Dogs.

Es cierto que los dibujos fueron hechos por Orozco exclusivamente con el objetivo de ilustrar la novela (es decir, sería impreciso hablar de convergencia, estrictamente hablando), pero habría que discutir hasta qué punto la lectura de Los de abajo condicionó la propuesta del pintor mexicano. Como he señalado a lo largo de este apartado, algunas ilustraciones son reelaboraciones de motivos recurrentes en la obra previa de José Clemente Orozco, aunque no por ello resultan ajenas al universo novelístico; a veces simplemente colman los vacíos que deja el estilo parco y elíptico del texto de Mariano Azuela. Y aun cuando a veces llegan a contradecir el mensaje verbal, las imágenes contribuyen a forjar una imagen más completa de la Revolución; en ese sentido, The Under Dogs es una obra distinta a Los de abajo. ${ }^{6}$

\section{Orozco, Azuela y el parto doloroso de México}

En un muy certero comentario interpretativo, Luis Cardoza y Aragón apunta que la obra orozquiana sugiere una conciencia horrorizada del parto de México sin ver despuntar el día (Cardoza, 1959: 208). El señalamiento sin duda vale para la forma como Mariano Azuela concibe la Revolución en Los de abajo: tanto el pintor como

\footnotetext{
${ }^{6}$ Aclaro que el análisis textual que se incluye en el siguiente apartado se basa en la versión en español de Los de abajo: en la versión en inglés de los fragmentos analizados no hay modificaciones con miras a adaptarse a las necesidades del público estadounidense; es decir, al menos en los pasajes citados, la versión en inglés no difiere de la versión en español en lo más mínimo.
} 
el novelista se ven atraídos por el rostro más feroz de la guerra, lo cual deja las arterias políticas y sociales en un sitio secundario, al contrario de lo que sucede con la obra de Diego Rivera y Gregorio López y Fuentes, por poner sobre la mesa un par de pintura-literatura más o menos equivalente. Esta forma de enfocar la Revolución, por cierto, les acarreó a Orozco y Azuela juicios adversos en un plano más ético que estético, ${ }^{7}$ aunque también fue clave para que sus respectivas propuestas artísticas coincidieran en un libro. ${ }^{8}$

Sin embargo, conviene no quedarnos con lo aparente, porque de lo contrario se corre el riesgo de simplificar la relación entre el texto y las ilustraciones atribuyéndoles a Orozco y Azuela una conexión psicológica, "desliz" que comete Alma Reed en su biografía (Reed, 1959: 152). Ciertamente ambos artistas construyen una revolución implacable, inconsciente de los límites que le otorga legitimidad, con lo que se distancian del discurso canónico, según el cual el pueblo cogió el fusil y regó el suelo con su "sangre bendita," según diría Pascual Ortiz Rubio (Ortiz, 1930: 157), con el objetivo único de defender "el decoro de la Patria Mexicana," según diría Álvaro Obregón (Obregón, 2002: 222). No obstante, como adver-

${ }^{7}$ Eduardo Colín, por ejemplo, señala los méritos literarios de Los de abajo, después de lo cual dice, a propósito de la trama, que la "esencia nacional, la Revolución misma, no es tan sólo guerra y sangre, sino otras cosas" (1973: 17). Sobre el empeño de Orozco por pintar imágenes sombrías, Ignacio de la Peña hace una crítica muy parecida a la de Colín: "una cosa es denunciar el lado horrendo de la verdad, y otra obstinarse en no ver otro" (1982: 116).

${ }^{8}$ Todo indica que la "obsesión" por la violencia fue tan determinante como el azar: según cuenta Víctor Díaz Arciniega, los agentes de la casa editorial Brentano, que se encargaría de la edición en inglés de Los de abajo, se acercaron primero a Diego Rivera, quien rechazó la invitación "porque ya estaba comprometido para una edición similar que se estaba preparando en México" (Díaz, 2012: 23), la cual, por cierto, nunca se publicó (tendrían que pasar más de ochenta años para que ocurriera: en el 2012, el Fondo de Cultura Económica y la Universidad Autónoma Metropolitana coeditaron Los de abajo con los dibujos que Rivera había hecho). 
tiremos a continuación, Orozco y Azuela ofrecen matices propios, que hablan de visiones distintas de la Revolución.

Donde el texto y las ilustraciones más se aproximan entre sí es en en la cabecera de cada una de las tres partes de la novela. En esa zona, las piezas de Orozco buscan sintetizar icónicamente el conjunto de capítulos cuya lectura el lector está por emprender; es decir, lo visual funge como síntesis y anticipación. Ésta es una muestra clara de cómo la imagen pone en práctica una de sus especificidades discursivas, pues busca concentrar en un pequeño recuadro lo que la novela expresa a lo largo de varias páginas.

La primera parte la anuncia un dibujo donde un campesino con sombrero de palma de ala ancha carga en sus brazos a una mujer descalza con trenzas, detrás de los cuales se exhibe una planta de maguey (figura 1) ${ }^{9}$, estampa recurrente en el imaginario orozquiano. En la cabecera de la segunda parte, la ilustración proyecta la pérdida del control del movimiento popular: en primero plano, un soldado revolucionario observa el padecimiento de un hombre que, a gatas y aparentemente desnudo, ha sufrido el furor de la Revolución, mientras que dos mujeres huyen de la soldadesca lúbrica (figura 2). Por último, el dibujo que abre la tercera parte de Los de abajo muestra un revolucionario detrás de una planta de maguey, todo parece indicar que escondido, lo que nos remite a la escena final de la obra (figura 3).

${ }^{9}$ El nombre y la cronología de muchas de las obras de caballete de José Clemente Orozco, sobre todo los dibujos, los grabados y las litografías, es incierto. Por esta razón, he optado por prescindir del nombre cuando aludo a las ilustraciones de la novela, cuyo título varía dependiendo de la fuente. 

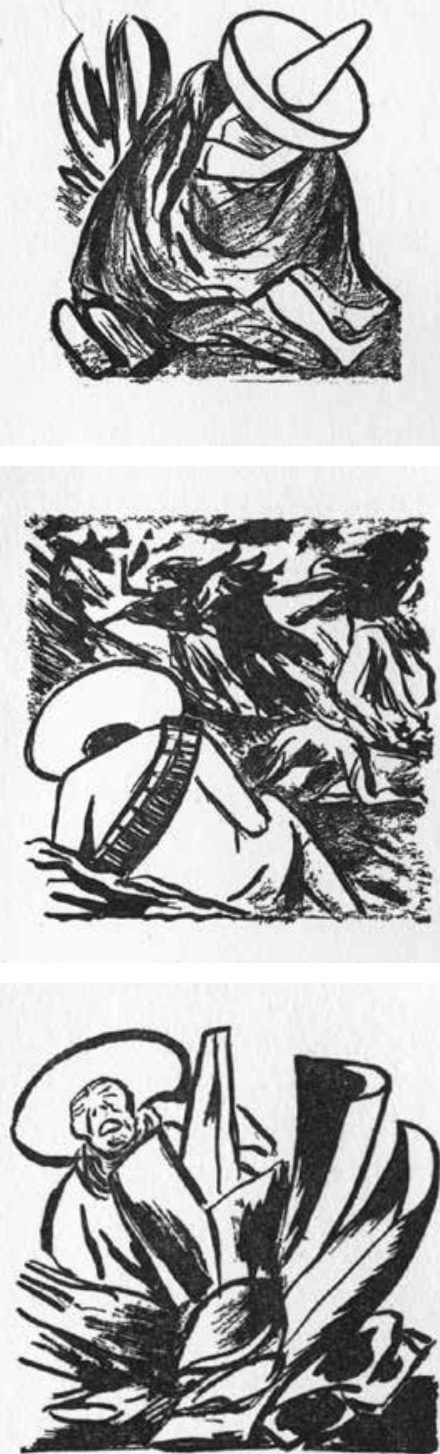

Figuras 1,2 y 3 . Ilustraciones de Los de abajo 
Estas tres ilustraciones secundan plásticamente, de forma muy esquemática, el proceso de degeneración del movimiento popular que traza la novela a través del desarrollo de la trama: en la primera parte, recordemos, Demetrio Matías se levanta en armas en reacción a los atropellos de don Mónico, cuya influencia se concreta en la destrucción de la casa del cabecilla; en la segunda, una vez que ha adquirido poder y renombre a raíz de la toma de Zacatecas, Demetrio y los suyos se abandonan a toda clase de excesos, y en la tercera parte, la cuadrilla, diezmada física y moralmente, vuelve a Juchipila, donde cae abatida. Los de abajo, pues, arranca concibiendo la Revolución como un "acto epifánico de búsqueda de la justicia” (Olea, 2012: 493) para convertirse, con el paso de los capítulos, en una sucesión redundante de cuadros de degradación. Como se dijo en el párrafo anterior, es en estas tres ilustraciones iniciales donde las respectivas propuestas de Orozco y de Azuela armonizan, pues el pintor consigue trazar ese arco "involutivo" en los dibujos con que se abre cada parte de la obra. En el resto de la novela, el dibujo y el texto ofrecen tonalidades y encuadres propios que derivan en concepciones distintas de la Revolución, si bien ambas tienden a destacar la violencia.

La segunda ilustración, que se sitúa al inicio del tercer capítulo de la primera parte, registra una batalla entre revolucionarios y federales en el característico estilo tenebroso orozquiano, amante de las deformidades y de las figuras afiladas (figura 4), un estilo, como diría Ermilo Abreu Gómez, en el que "todo se quiebra en ángulos" (1982: 55). La ilustración discuerda del tono socarrón con que se narra la primera batalla que protagoniza la cuadrilla de Demetrio Macías, tono al que contribuye el diálogo de los campesinos armados, a través del cual convierten la escaramuza en un macabro pero jovial juego de puntería y apuestas. La ilustración, por el contrario, carece de humor: la muerte, la angustia, el tumulto, el padecimiento físico y los cuchillos en alto lo aca- 
paran todo. Por otra parte, la confusión de los cuerpos en pugna, tan común en la obra de Orozco, obstaculiza la interpretación épica: ${ }^{10}$ el ojo no alcanza a diferenciar entre actos reivindicativos y actos de explotación; todo es una única gran violencia, voraz, en la que se disuelve cualquier atisbo de perspectiva política, social. Ahora bien, la divergencia entre imagen y texto se reduce en la siguiente ilustración, donde aparecen un colgado y, debajo de él, tres cuerpos (figura 5). El semblante ensombrecido del colgado, así como la ausencia de ropa, la dislocación de uno de los cuerpos y la sobriedad del paisaje, crean una atmósfera aterradora, que, de nueva cuenta, dificulta la lectura épica; más que la dignidad de un movimiento revolucionario, la ilustración muestra la degradación, espiritual y corporal, a la que conduce la guerra. En el capítulo IV de la primera parte de Los de abajo hay una imagen muy similar, dos miembros de la cuadrilla de Demetrio Macías son colgados por los federales, descritos así: "Las siluetas de los ahorcados, con el cuello flácido, los brazos pendientes, rígidas las piernas, suavemente mecidos por el viento" (44).

Con las dos ilustraciones siguientes, José Clemente Orozco se aparta de una concepción lineal-causal de la lucha armada, concepción que se halla sugerida en Los de abajo: para el pintor, no es que la Revolución se haya pervertido en el trayecto y la violencia desproporcionada sea evidencia de ello, sino que su poder destructivo es consustancial a la guerra, independientemente de sus fundamentos; en esas dos ilustraciones, en otras palabras, no se es-

${ }^{10}$ Para Mercedes Comellas, una de las características del relato épico es la existencia de una sola perspectiva narrativa, que es absoluta e inalterable y tiende a corresponderse con lo social, cultural y políticamente hegemónico: "Los defensores están siempre identificados con el punto de vista de la narración, y por supuesto con el nosotros que se quiere distinguir de los otros, el enemigo peligroso con el que sólo cabe un enfrentamiento violento pero sancionado y autorizado por la moral y el poder" (2012: 225). Cuando empleo el término épica, aludo a la definición de Comellas. 

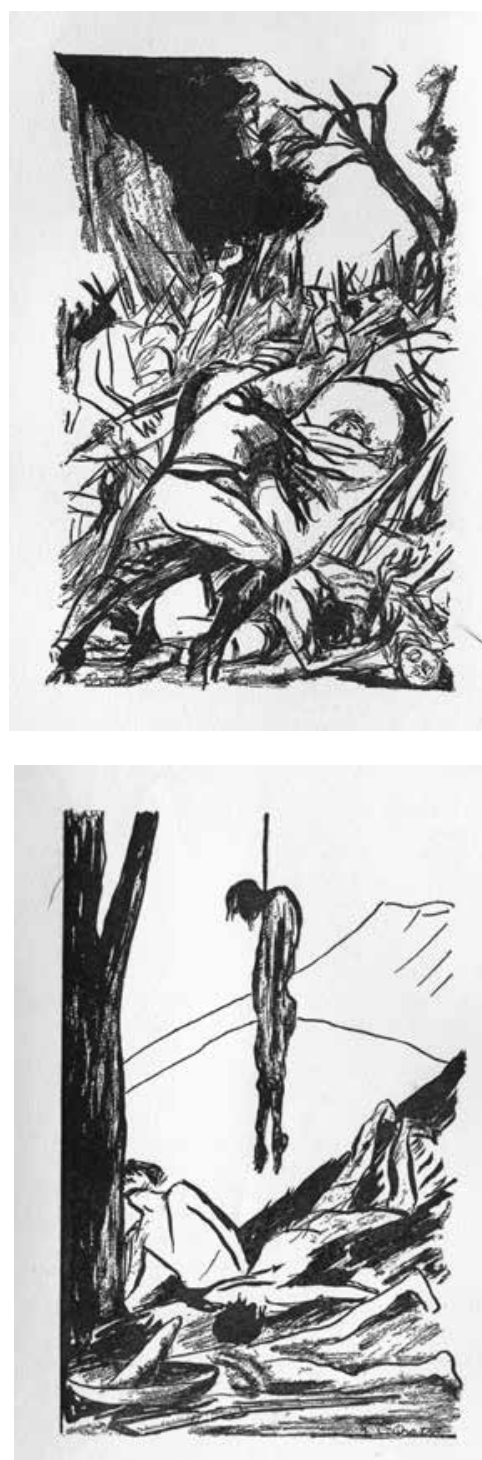

Figura 4 y 5. Ilustraciones de Los de abajo 
cudriñan las causas de la guerra, sino que son, simple y llanamente, "un terrible enjuiciamiento de la raza humana" (Reed, 1959: 44). La novela, por el contrario, esboza un contexto que le sirve a la violencia como respaldo, lo cual permite exhibirla, al menos en los primeros capítulos, como una fuerza reactiva, punitiva y, por lo tanto, justificada:

— ¡Dios los bendiga! ¡Dios los ayude y los lleve por buen camino!... Ahora van ustedes, mañana correremos nosotros también, huyendo de la leva, perseguidos por estos condenados del gobierno, que nos han declarado guerra a muerte a todos los pobres, que nos roban nuestros puercos, nuestras gallinas y hasta el maicito que tenemos para comer, que queman nuestras casas y se llevan nuestras mujeres y que, por fin, donde dan con uno, allí lo acaban como si fuera perro del mal (Azuela, 1996b: 15).

La queja en coro del populacho frente a la marcha de Demetrio deja claro que los federales monopolizan las formas negativas de la violencia: roban, persiguen, humillan, destruyen, violan, asesinan. Esta monopolización atenúa el exceso y la trivialización de la violencia en los que de hecho caen los improvisados revolucionarios desde las primeras páginas. La exclamación de los serranos refuerza la perspectiva colectiva de la primera parte de la novela: ahora van ustedes; mańana nosotros. $\mathrm{Al}$ menos por el momento, Demetrio y el pueblo son una sola entidad; la inconsciencia y la ignorancia del cabecilla carecen de importancia porque, como suele ocurrir con el héroe de las epopeyas, sus actos expresan menos un afán individual que la voluntad y el anhelo de los que representa (Avechuco, 2016: 105). Los dibujos de Orozco, en cambio, no incluyen entidad alguna cuyos clamores legitimen cierto proceder; para el pintor parece existir una única e insaciable violencia. Las siguientes palabras, que fueron emitidas como parte de un diálogo que tuviera en Nueva York con Eva Sikelianós - esposa del poeta griego 
Ángelos Sikelianós-, ejemplifican bien su postura ante la guerra y la violencia:

En la tragedia de la guerra, importan poco el tiempo y el lugar. En México, los revolucionarios vestían de huarache y sombrero, cuando los tenían. Los antiguos guerreros griegos llevaban cascos de blanca cimera y sandalias clásicas. Pero en ambas épocas el sufrimiento fue igual [...] Dondequiera que se presente, el desperdicio de juventud es igualmente insensato. La crueldad, la brutalidad, la estupidez, son las mismas en todos los países y en todas las épocas (Apud. Reed, 1959: 44)

Si bien lo apuntado hasta el momento puede deberse a diferencias semióticas (la literatura es el arte del tiempo; la plástica, de los instantes y el espacio), considero que el proceso de degradación que desarrolla la novela y la visión más estática de las ilustraciones están condicionadas menos por las especificidades discursivas de cada medio que por la forma como Mariano Azuela y José Clemente Orozco conciben tanto la Revolución como su contingente más numeroso, es decir, el sector popular. En su autobiografía, Orozco le dedica muy pocas líneas a la lucha armada, en las cuales, sin embargo, se trasluce la honda impresión que le causaron la fuerza y el poder destructivo del movimiento, que testimonió cuando estuvo en Orizaba, Veracruz, trabajando para La Vanguardia junto al Doctor Atl. Esa impresión es tal, que no hay espacio para la queja política ni mucho menos para comentarios trascendentalistas sobre las bases virtuosas de la Revolución. Se impone lo inmediato por encima de todo. El recuerdo de la realidad material obnubila:

Tropas iban por las vías férreas al matadero. Los trenes eran volados. Se fusilaba en el atrio de la parroquia a infelices peones zapatistas que caían prisioneros de los carrancistas. Se acostumbraba la gente a la matanza, al egoísmo más despiadado, al hartazgo de los sentidos, a la animalidad pura y sin tapujos. Las poblaciones 
pequeñas eran asaltadas y se cometía toda clase de excesos. Los trenes que venían de los campos de batalla vaciaban en la estación de Orizaba su cargamento de heridos y de tropas cansadas, agotadas, hechas pedazos, sudorosas, deshilachadas [...] Un desfile de camillas con heridos envueltos en trapos sanguinolentos y de pronto el repicar salvaje de las campanas y tronar de balazos. Tambores y cornetas tocando una diana ahogada por el griterío de la multitud dando vivas a Obregón. ¡Muera Villa! ¡Viva Carranza! "La Cucaracha" coreada a balazos (Orozco, 2002: 43-44).

Tanto en este fragmento como en las piezas de los Horrores y en las ilustraciones de Los de abajo, Orozco nos esconde los fundamentos políticos y las motivaciones sociales de la guerra, lo que contribuye a generar imágenes de caos, cuya lógica, nunca binaria ni lineal, impide concebir el proceso revolucionario en términos de degradación. Y es que para que haya degradación, debe haber primero integridad, aunque sea puramente teórica; la guerra, en otras palabras, es un error en sí misma, de principio a fin. Insisto: esta percepción estática, que le da la espalda al arco de acenso y descenso que traza la novela, es más producto de la valoración orozquiana del proceso revolucionario que el resultado de los límites de representación del código visual, que, por cierto, tiene sus estrategias para producir el sentido de la sucesión y la temporalidad.

Mariano Azuela, en cambio, es un decepcionado de la Revolución, como él mismo sostiene: "tuve ocasiones sobradas para observar desapasionadamente el mundo de la revolución. Muy pronto la primitiva y favorable impresión que tenía de sus hombres se fue desvaneciendo en un cuadro de sombrío desencanto y pesar" (Azuela, 1996a: 326). En Los de abajo, el personaje Alberto Solís, la síntesis ideológica e intelectual de la obra (Ruffinelli, 1196: XLII), concreta estéticamente ese cuadro de sombrío desencanto y pesar al que alude el novelista. Solís funge de hermeneuta: mediante sus breves pero significativas intervenciones, desentraña el comportamiento de los 
ejércitos populares apelando a un muy positivista análisis caracterológico del mexicano: "la psicología de nuestra raza, condensada en dos palabras: ¡robar, matar!” (Azuela, 1996b: 71). Este contrito dictamen lo convalida la novela, que en su segunda parte yuxtapone cuadros de anarquía -saqueo, destrucción de espacios civiles, asesinatos arbitrarios, estupro- y episodios donde se exhibe la falta de cultura letrada de la cuadrilla, como cuando la Codorniz arranca los grabados de la Divina Comedia, en los que solamente alcanza a detectar "vieja encuerada" (Azuela, 1996b: 80). Los de abajo, de esta manera, estetiza el conflicto del liberal característico de la coyuntura revolucionaria, ese que defiende la Revolución como entidad abstracta, ideal, pletórica de bondades, pero que a la vez abomina de las conductas que perturban el orden constitucional. Es muy posible que Orozco experimentara ese conflicto, pero en todo caso su obra no parece confirmarlo, como sí ocurre en Los de abajo, donde la violencia popular produce un llanto más político que humanista y ratifica, si se quiere indirectamente, las virtudes de la razón como eje vertebrador de una revolución soñada.

Ahora bien, considero que son otras las imágenes que más se distancian de la propuesta de Los de abajo. Me refiero, específicamente, a la cuarta, penúltima y última ilustración, las cuales se caracterizan por representar ya no alguna forma de desorden, sino sus secuelas. La cuarta imagen consiste en una estampa representativa de la iconografía orozquiana: una procesión de campesinos armados en la que destacan mujeres que cargan a sus hijos en rebosos a la espalda, andan encorvadas y miran al suelo (figura 6). El dibujo, que testimonia el desarraigo y la errancia que propició la Revolución, procura un acento melancólico que la novela desatiende, dado que son otras sus preocupaciones. En Los de abajo hay desarraigo y errancia, por supuesto, pero la novela los transforma en imágenes de emancipación con ecos primitivistas, como la del siguiente fragmento: 
Los soldados caminan por el abrupto peñascal contagiado de la alegría de la mañana. Nadie piensa en la artera bala que puede estarlo esperando más adelante. La gran alegría de la partida estriba cabalmente en lo imprevisto. Y por eso los soldados cantan, ríen y charlan locamente. En su alma rebulle el alma de las viejas tribus nómadas. Nada importa saber adónde van y de dónde vienen; lo necesario es caminar, caminar siempre, no estacionarse jamás; ser dueños del valle, de las planicies, de la sierra y de todo lo que la vista abarca (Azuela, 1996b: 138).

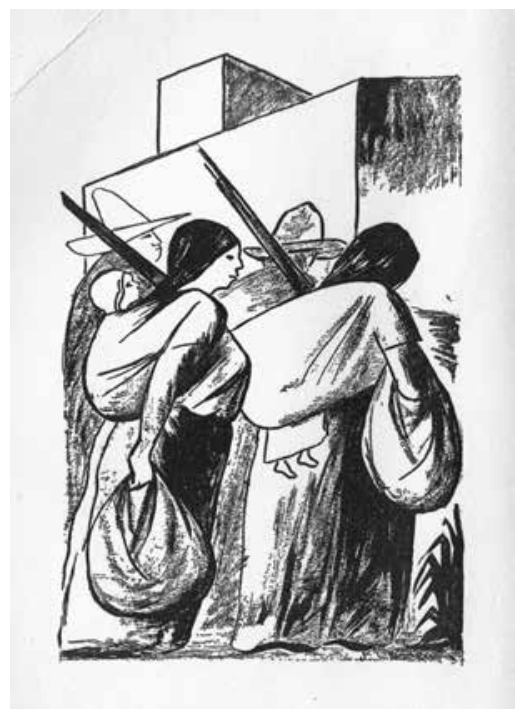

Figura 6: ilustración de Los de abajo

Salvo el momento inicial, cuando los federales queman la casa de Demetrio y éste se despide de su esposa, Los de abajo tiende a hacer hincapié en el hecho de que el exilio forzado del hogar es una puerta a la libertad, por más que ésta tome la forma de la venganza, la apropiación de espacios ajenos y otras formas de violencia. La ilustración de Orozco, por el contrario, señala el sentido de pérdida, de ahí los cuerpos encorvados, los semblantes circunspectos y la mirada enca- 
jada en el suelo. Este sentido de la pérdida es recurrente en la obra del pintor, como puede verificarse en La despedida y La retaguardia, litografías de 1928 y 1929 respectivamente (elaboradas a partir de sendas piezas de los Horrores de la Revolución).

La recurrencia de esta imagen de pérdida y desarraigo en el imaginario orozquiano de alguna forma constata que la ilustración no está inspirada en Los de abajo, lo que es otro modo de decir que es un aporte de Orozco al universo novelístico de Mariano Azuela. Lo mismo sucede con la penúltima ilustración, en la cual dos revolucionarios asisten a un tercero mientras una mujer se tapa el rostro en un ademán de pesar (figura 7), y la última, donde tres figuras, solemnes frente al tronco de un árbol marcado con una cruz, protagonizan lo que parece ser una escena de duelo (figura 8).

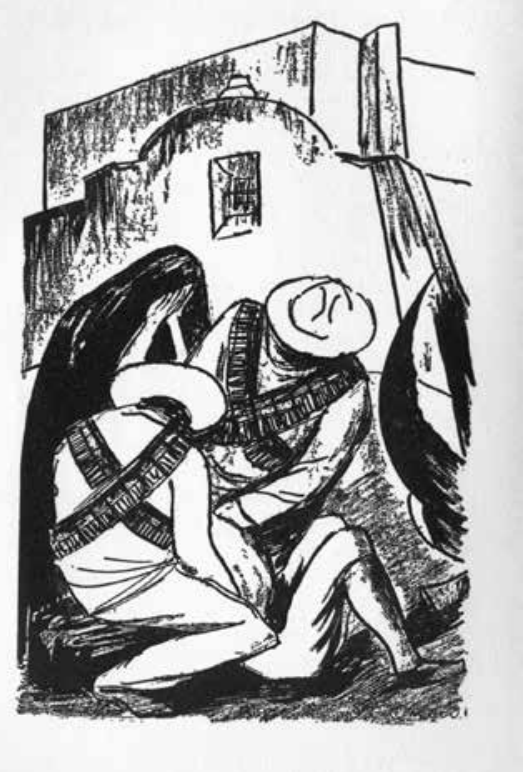

Figura 7: ilustración de Los de abajo 


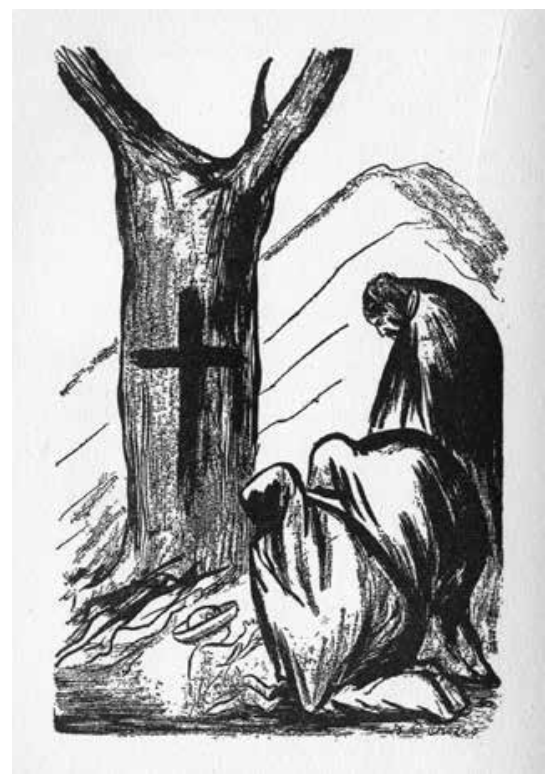

Figura 8: ilustración de Los de abajo

Según observamos, en estos dos dibujos vuelve a destacarse el sentido de la pérdida, encarnada ahora no en el desarraigo, sino en la muerte. Por un momento Orozco suspende su fascinación por la violencia para compadecerse de los hombres y las mujeres que ven perecer a los suyos. La segunda de estas ilustraciones, además, expele una atmósfera lúgubre e incluso siniestra que, de nuevo, recuerda otras obras del pintor mexicano, como Réquiem y Guerra, ambas pertenecientes a la serie Horrores de la Revolución.

Como bien señala Elizabeth García Guajardo, Los de abajo tiene momentos melancólicos y ligeramente lúgubres (García, 2001: 52), como cuando la gavilla de Demetrio Macías, hacia el final de la obra, regresa a Juchipila, cuyo templo dejaba escapar "las voces melifluas de un coro femenino," que cantaban los "Misterios" acompañadas de "los acordes de un guitarrón" (Azuela, 1996b: 175). Sin embargo, en esta escena, la novela llora no necesaria- 
mente por las pérdidas humanas, sino por la agonía de la revolución tal como la plantea el texto en sus primeras páginas: no es coincidencia que estas tenues manifestaciones de melancolía y lobreguez lleguen en las últimas páginas de la obra. De hecho, en ese momento los hombres de la tropa caen en la cuenta de que se está cumpliendo un año de la toma de Zacatecas, cresta del movimiento popular que encabeza Macías, y eso los pone tristes; no es pena lo que sienten, sino nostalgia de tiempos mejores, cuando la revolución gozaba de salud.

En la primera y segunda parte, Los de abajo se detiene en las imágenes de muerte, sí, pero no para destacar el duelo; la muerte, más bien, le es útil al narrador en la medida en que le permite apuntalar la configuración de los personajes, en especial de los campesinos que nutren la cuadrilla de Demetrio Macías. Por eso la novela prefiere capturar el instante en que la vida expira, como cuando el machete de Demetrio se topa con las costillas de un viejo de "cara indígena llena de arrugas," quien cae con "los brazos abiertos y los ojos espantados" (1996b: 58), o como cuando la cuadrilla, ya perdido el rumbo, cuelga a un "pobre diablo de cura," al pie del cual queda "un reguero de muertos" (1996b: 101). En esta clase de imágenes no importa tanto la muerte como el acto violento cada vez más desproporcionado y arbitrario que le precede, el cual acentúa, desde la perspectiva de la novela, el enviciamiento de la revolución popular. Ni siquiera el saldo trágico de una prolongada batalla, como la que se da en el cerro de la Bufa, fundamental para la toma de Zacatecas, suscita la condolencia del narrador, quien, más bien, aprovecha la oportunidad para ratificar sus premisas sobre la revolución popular:

La vertiente, de seiscientos metros, estaba cubierta de muertos, con los cabellos enmarañados, manchadas las ropas de tierra y de sangre, y en aquel hacinamiento de cadáveres calientes, mujeres 
haraposas iban y venían como famélicos coyotes esculcando y despojando (1996b: 71).

Mientras que en las dos ilustraciones anteriores los cuerpos de Orozco son envueltos por el luto, los de Mariano Azuela suponen meros despojos alrededor de los cuales se arremolinan unas adelitas con hábitos de animal carroñero. Se trata de dos imágenes muy diferentes pero a la vez complementarias, puesto que ambas apuntan a la fuerza demoledora de la Revolución.

Lejos de limitarse a darle presencia gráfica a algunos pasajes capitales de Los de abajo, Orozco contribuye a robustecer la imagen novelística de la Revolución, entendida ésta como un conglomerado de ideas y sucesos contradictorios y a la vez complementarios, que, por lo tanto, suele rehusar las representaciones monolíticas. Según se observó, el lápiz del pintor mexicano enriquece el sentido de la lucha armada generado por el texto inoculándole un aire más trágico que decepcionado y dotándolo de una atmósfera lóbrega y de una mirada a veces conmiserativa.

\section{Conclusiones: ni profetas ni rapsodas}

El clima nacionalista que impera en el entorno político, intelectual y cultural durante el periodo posrevolucionario permea, por supuesto, el ámbito de la crítica, cuyas prácticas manifiestan "una cierta dependencia, o para ser más preciso, apunta a la dificultad -en esta época- de pensar la realidad del país al margen del discurso político integracionista del Estado mexicano" (Parra, 2013: 5-6). Especialmente a partir de la administración de Plutarco Elías Calles, el Estado y los círculos intelectuales que le son afines propician un ambiente de promoción y difusión de obras artísticas donde se preconiza ya no sólo la temática revolucionaria, la cual simplemente se presupone, sino también cierta perspectiva, cierto 
tono y cierto estilo; se definen, pues, criterios que de alguna manera garanticen un producto artístico que encumbre la Revolución, incluso aquellos animados por un espíritu crítico, motivo por el cual Díaz Arciniega asevera que detrás de esos criterios de validación hay más una propuesta política que estética (2010: 128). ${ }^{11}$

Ahora bien, ocurrió muy a menudo que cuando una obra de considerable calado no se ajustaba a los criterios de validación, la crítica, conscientemente o víctima de la inercia interpretativa, se encargaba de forzar su lectura nacionalista. Ni la obra de Mariano Azuela ni la de José Clemente Orozco salieron incólumes de estas prácticas. Del primero, apenas fue descubierto por la intelectualidad capitalina, se dijo que con su obra manifestaba "un hondo sentido de lo nuestro" (Jiménez, 1973: 11); años más tarde, cuando Azuela ya formaba parte del santoral de la literatura mexicana, los comentaristas se dejaron de tibiezas para proclamar que Los de abajo tenía "por germen el alto, purísimo amor por la patria" (González, 1973: 121). Orozco fue descrito por José Juan Tablada ni más ni menos que como el "rapsoda del pueblo mexicano," que "ha contribuido a esclarecer los móviles de justicia y humanidad que han animado a nuestra patria" (Tablada, 1929: 1). De esta forma, la crítica nacionalista acabó convirtiendo a determinados artistas en "reveladores del espíritu de nuestra raza” (Amábilis, 1925: 2), en creadores que, con "la expresión no más diestra sino más honda," son "capaces de alcanzar y penetrar la conciencia de México," en hombres, pues, que no "vuelven la espalda al espíritu del país" (Abreu, 1999: 443). Esta tendencia a la sublimación de la obra y de los autores - basada con frecuencia en la tergiversación y

${ }^{11}$ Cabe aclarar que esos criterios de validación encontraron resistencia en artistas, críticos, filósofos e intelectuales cuya concepción del arte iba en contra de los postulados nacionalistas más epidérmicos (como los llamaría Rufino Tamayo). Para profundizar en el desarrollo del debate que protagonizaron ambas posturas, véase México en 1932: la polémica nacionalista, de Guillermo Sheridan. 
en el cercenamiento del sentido- propició la homogeneización y la simplificación del producto artístico con temática revolucionaria, como lo demuestran las palabras de, por ejemplo, Luis Cardoza y Aragón, para quien la literatura y la pintura de la época poseen el mismo "plano moral e intelectual" (Cardoza, 1935: 32), apunte que no desarrolla ni resulta de análisis alguno.

Si bien la crítica nacionalista comenzó a perder fuerza en la década de los sesenta, su poder había sido tal, que su interpretación de ciertas obras, en especial aquellas consideradas "muy mexicanas," se perpetuó. Esto de alguna manera ha entorpecido el análisis no sólo de las creaciones artísticas como productos autónomos, a muchas de las cuales se les continúa dando tratamiento de lábaros patrios, sino también de los complejos vínculos entre ellas. ${ }^{12}$ Como pudimos observar a lo largo de este trabajo, Mariano Azuela y José Clemente Orozco se hallan muy lejos de ser profetas de la raza mexicana o rapsodas de la gesta revolucionaria: sus reelaboraciones estéticas de la lucha armada, diferentes pero casi siempre complementarias, son proyección de una consciencia o pesarosa o fascinada ante la presencia de una terrible monstruo que, cual deidad primitiva, es destructor y creador a un mismo tiempo.

\section{Bibliografía}

Abreu Gómez, Ermilo, 1999, "El año artístico 1932 y las nuevas corrientes literarias en México", en México en 1932: la polémica nacionalista, Guillermo Sheridan (ed.), Fondo de Cultura Económica, México, pp. 440-446.

${ }^{12}$ Afortunadamente, en los últimos tiempos han surgido estudios que buscan colmar el vacío. Véase, por ejemplo, Equestrian Rebels: Critical Perspectives on Mariano Azuela and the Novel of the Revolution, de Roberto Cantú, e Imagining the Mexican Revolution: Versions and Visions in Literature and Visual Culture, de Tilmann Altenberg. 
, 1982, "Sala de retratos: 'José Clemente Orozco", en José Clemente Orozco: antología critica, Teresa del Conde (ed.), unam, México, pp. 55-58.

Alvarado, Maite, s. f., Paratexto, Universidad de Buenos Aires, Argentina. Disponible en: https://tallerproduccionoralyescrita. files.wordpress.com/2011/03/paratexto-maite-alvarado.pdf

Amábilis, Manuel, 1925, “Diego Rivera y su obra”, El arquitecto, vol. 5, núm. 2, México, pp. 1-2.

Avechuco Cabrera, Daniel, 2016, "Campesinos héroes, campesinos primitivos: representaciones de la violencia en Los de abajo, de Mariano Azuela”, en $A$ cien años de Los de abajo: relecturas y nuevos acercamientos, Francisco Gerardo Bobadilla Encinas (coord.), Orfila, México, pp. 99-129.

Azuela, Mariano, The Under Dogs: a Novel of the Mexican Revolution, Enrique Munguía (trad.) y José Clemente Orozco (ilustrador), Brentano's, Nueva York, 1929.

, 1991, Epistolario y archivo, UNAM, México.

, 1996a, "Los de abajo", en Mariano Azuela, Los de abajo, Jorge Ruffinelli (ed. y coord.), Conaculta/FCE/ALlCA Xx, Colección Archivos 54, París, pp. 336-338.

, 1996b, Los de abajo, Jorge Ruffinelli (ed. y coord.), Conaculta/FCE/ALlCa Xx, Colección Archivos 54, París.

Cantú, Roberto, 2016, Equestral Rebels: Critical Perspectives on Mariano Azuela and the Novel of the Revolution, Cambridge Scholars Publishing, Cambridge.

Cardoza y Aragón, Luis, 1935, “Arte y Revolución”, U. G. B.: Revista de Cultura Moderna, núm. 2, México, pp. 28-41.

, 1953, Pintura mexicana contemporánea, Imprenta Universitaria, México.

, 1959, Orozco, unam, México. 
Colín, Eduardo, 1973, "Los de abajo”, en Mariano Azuela y la crítica mexicana. Estudios, artículos y reseñas, Francisco Monterde (coord.), sep, México, pp. 15-17.

Comellas, Mercedes, 2012, "De la muerte de la épica a la muerte de la historia: literatura y violencia", en La violencia en la Historia: análisis del pasado y perspectiva sobre el mundo actual, Juan José Iglesias Rodríguez (ed.), Universidad de Huelva, Huelva, pp. 213-274.

Díaz Arciniega, Víctor, 2010, Querella por la cultura “revolucionaria” (1925), FCE, México.

, 2012, "Prólogo", en Mariano Azuela, Los de abajo (con dibujos de Diego Rivera), unam/uam-A/FCE, México, pp. 9-25.

García Guajardo, Elizabeth, 2010, Mariano Azuela y José Clemente Orozco: imágenes de la Revolución, San José State University, San José, (tesis Master of Arts in Spanish).

Genette, Gérard, 2001, Umbrales, Susana Lage (trad.), Siglo XxI, México.

González de Mendoza, J. M., 1973, "La garra de Mariano azuela", en Mariano Azuela y la critica mexicana. Estudios, artículos y reseñas, Francisco Monterde (coord.), sep, México, pp. 160-164.

Indych, Anna, 2001, "Made for the USA: Orozco's Horrores de la Revolución", Anales del Instituto de Investigaciones Estéticas, vol. 23, núm. 79, México, pp. 153-164.

2009, Muralism without Walls. Rivera, Orozco, and Siqueiros in The United States, 1927-1940, The University of Pittsburgh Press, Pittsburgh.

Jiménez Rueda, Julio, 1973, “El premio nacional”, en Mariano Azuela y la crítica mexicana. Estudios, artículos y reseñas, Francisco Monterde (coord.), sEP, México, pp. 108-111.

Monsiváis, Carlos, 1981, "Orozco”, Nexos. Disponible en: https:// www.nexos.com.mx/?p=4282 (Consultado el 5/I/2018). 
Obregón, Álvaro, 1932, Discursos del General Álvaro Obregón, Biblioteca de la Dirección General de Educación Militar, México.

Olea Franco, Rafael, 2012, "La novela de la Revolución mexicana: una propuesta de relectura", Nueva Revista de Filología Hispáni$c a$, vol. 60, núm. 2, México, 479-514.

Orozco, José Clemente, 1987, Cartas a Margarita (1921-1949), Tatiana Herrero Orozco (pre., sel. y notas), Era, México.

, 1993, José Clemente Orozco: el artista en Nueva York (cartas a Jean Charlot 1925-1929 y tres textos inéditos), Siglo XxI, México.

, 2002, Autobiografía, Joaquín Mortiz, México.

Ortiz Rubio, Pascual, 1930, Discursos politicos, s. e., México.

Parra, Max, 2013, "Geografía y procesos culturales en la narrativa de la Revolución Mexicana (Azuela y Campobello)”, en Imagining the Mexican Revolution: Versions and Visions in Literature and Visual Culture, Tilmann Altenberg (ed.), Cambridge Scholars Publishing, Newcastle, pp. 3-18.

Paz, Octavio, 1987, "Ocultación y descubrimiento de Orozco", en México en la obra de Octavio Paz III. Los privilegios de la vista. Arte de México, FCE, México.

Peña Pedroza, Ignacio de la, 1982, "Orozco bajo el psicoanálisis", en José Clemente Orozco: antología critica, Teresa del Conde (ed.), unam, México, pp. 113-129.

Pupo-Walker, Enrique, 1967, "Los de abajo y la pintura de Orozco: un caso de correspondencias estéticas", Cuadernos Americanos, núm. 154, México, pp. 237-254.

Reed, Alma, 1955, Orozco, Jesús Amaya Topete (trad.), FCE, México.

Ruffinelli, Jorge. "La recepción crítica de Los de abajo", en Mariano Azuela, Los de abajo, Jorge Ruffinelli (ed. y coord.), Conaculta/ fCE/AllCa XX, Colección Archivos 54, París, pp. 231-259. 
Sheridan, Guillermo, 1999, México en 1932: la polémica nacionalista, FCE, México.

Tablada, José Juan, 1929, “Arte y Revolución”, El Universal, 7 de marzo, México, p. 3.

, 1981, "Orozco, el Goya mexicano", en José Clemente Orozco: antología critica, Teresa del Conde (ed.), Instituto de Investigaciones Estéticas, México. 